\title{
Assessment of Training and Development Practice the Case of Human Rights Commission Hawassa Branch
}

Asfaw Takele Feleke ${ }^{1}$

${ }^{\prime}$ Ethiopian Human Rights Commission, Ethiopia

Email:takeleasfaw279@gmail.com

Licensed:

This work is licensed under a Creative Commons Attribution 4.0 License.

Keywords:

Trainers

Trainees

Jobs

Development

Assessment

Determining

Etc.

\begin{abstract}
Training practice and development is very crucial to workers to develop their career while they are engaged in their occupation in particular and the organization or institution in general. Unfortunately, the researcher had hesitated that training practices and development is done well in Hawssa branch. So, the researcher planned to solve the hesitation and did accordingly. The researcher set the assessment of the current the training and development practice and tits importance as a purpose and investigate the findings accordingly in the selected case study organization. The research study is designed to bring an importance of informing the commission about the current training and development practice and in turn, make insured about the civil service policy practice. The researcher used qualitative and quantitative type of study with primary ${ }^{\circ}$ secondary data collection mechanisms. In addition the researcher used purposive sampling methodology with 100\% size population sample and triangulation mechanisms of data analysis methods. The research study used surveying different literatures and in turn reviewing the differences between what the sciences says and the existed current training and development practice of the commission with the selected case study area. At last the researcher with its study of this research concluded the article with important summary.
\end{abstract}

\section{Introduction}

Training practice and development is very crucial to workers to develop their career while they are engaged in their occupation in particular and the organization or institution in general. There are a lot of ways; of course, these workers can develop their professional career. However, as different scholars addresses' training practice and development is the best way to do better than the others. Unfortunately, the researcher had hesitated that training practices and development is done well in Hawssa branch. That is why he initiated and stands to conduct research essay in order to investigate put up recommendation on it. The detail contentment, therefore, provided as follows.

\subsection{Back Ground of the Study}

Organizations are living systems, in a constant state of dynamic evolution (Sharon \& Elwood, 2015). According to these individuals, New Perspectives in Organizational Learning, Performance, and Change is designed to showcase the most current theory and practice in human resource and organizational development, exploring all aspects of the field-from performance management to adult learning to corporate culture. Integrating cutting-edge research and innovative management practice, this library of titles will serve as an essential resource for human resource professionals, educators, students, and managers in all types of organizations.

Beyond this, in the field of Human Resources Management, Training and Development is the field concerned with organizational activities which are aimed to bettering individual and group performances in organizational settings. Training needs to be analyzed as it fills in the gap between what is happening and what should happen.

All learning and training need to be based on an understanding of what needs to be done and why it needs to be done. Learning needs should be analyzed, first by the organization as a whole (corporate needs); second by their departments, teams within the organization (group needs) and third for an individual employees (individual needs) (Armstrong, 2003). 
Though the amount, and quality, of training carried out varies from one organization to another every organization faced with an issue called training and development. Following are the factors which influence the quantity and quality of training and development activities:

Training programs are important as it enables a new recruit to become productive as quickly as possible. It may consist of short term formal on the job coaching, a series of job rotations, training modules or a lengthy training like apprenticeships. Every training program needs to be designed individually, and the design will continually evolve as new learning needs emerge, or when feedback indicates that changes are required. (Armstrongs, 2006). However the target of this Study Hwassa Branch didn't show this. This means, though the commission identify that workers luck the necessary skill, attitude, and knowledge regarding to their works, it cannot preceded a head towards the problem. This is the reason why the researcher initiated to conduct this research essay and in turn providing the recommendation so as solve the problem for ever if possible or to minimize from the current situation. This essay, therefore, contains four chapters and is described as follows.

\subsection{Statement of the Problem}

Training and development of human resources leads to improvement of employee's performance, which let the organization, achieve efficiency and effectiveness. Training should be designed as part of a policy and strategy, the training strategy is an essential reference for the annual training plan and sets all training activities exactly in the context of strategic goals and organizational needs. The training function needs to help the organization develop a strong training culture, and training and development as an important resource to the organization.

Hawassa Branch which is responsible to serve the citizens and peoples of the region by promoting, protecting and enforcing the human and democratic rights of citizen. To effectively achieve this responsibility, Branch focuses on the development of employees to have skills, knowledge, attitudes and talents to serve the customer as they needed. The commission takes initiative to give training and development for its employees as strategic issue.

Developing the capacity of staffs has a number of advantages for any organization. The Hawassa branch has also providing capacity building activities to its staff members. As it has been complained by the employees the training and development program of the Hawassa branch are not properly planned, structured, and executed in the manner which solve performance related issues. Thus, the researcher would like to conduct an assessment of the entire training and development program of the commission to make some concluding remarks and follow up recommendations.

\subsection{Objective of Study}

This proposal is designed to solve the following general and specific objectives. These are:

\subsubsection{General Objective}

Generally, this essay assesses the training and development practice and their importance in the Hawassa branch.

\subsubsection{Specific Objectives}

Specifically, this study intended to address the following objectives:

- To evaluate the importance of training and development practice;

- To identify the mechanisms of conducting training and developments practices;

- To evaluate the types of training practices that will endure good career development on the employees of the EHRC Hawassa branch;

- $\quad$ To assess and identify gaps related with human resource training and development practices.

\subsection{Significance of the Study}

Beside its academic Benefits (Such as helping learners being aware about the importance of training, and help the commission to be informed about the necessity of providing planned, continuous, and well developed training practices. Second, impart the above stated objectives it touches the civil service reform policy program rationales. Which means, this study as far as deals with training practices and development, so that it results on the good implementation of the policy of the country set on enduring the workers continuous on job training needs?

\subsection{Scope/Delimitation of the Study}

Training and development or this investigation has conceptual and geographic delimits. Conceptually:- it only intends to investigate the current practices of training and development practice of professionals' career development and providing important suggestions. Geographically: - this study is totally limited to the administrative boundary of the EHRC Hawassa branch particularly on professional staff. 


\subsection{Limitation of the Study if Any}

The researcher might face with the following limitations or constraints. These are:

\section{Time Constraints}

As far as the researcher is a fully employed professional he might face with shortage of time to devote to this research.

\section{Budget Constraints}

As far as the researcher conducts the research self fully sponsoring shortage of budget to finance the research activities might be considered as a constraint.

\section{Information Barrier}

As the EHRC Hawassa branch is a recently opened, the researcher might face lack of the necessary data for the study.

\subsection{Research design and Methodology}

\subsubsection{Research Design and Methodology}

In this research explanatory research approach will be employed. This is because is need to explaining what the training and development practice look like, what outcome obtained through good training and development practice, and what would result if the training and development practices program are not conducted?

This research is both qualitative and quantitative research type. This research as the researcher state above assesses the existing case. So its research design is an explanatory.

\subsubsection{Method of Data Collection}

A. Primary Data Source: - Specific samples are taken from:

1. The workers who live and work in EHRC Hawassa Branch. Because they are one of the affected groups;

2. The middle and top level managements of the commission. So the methods which the researcher plans to use to collect data from these units of population are:

A. Closed Ended as well as Open ended questionnaires;

B. Unstructured and Semi-Structured Interview.

B. For Secondary data Source:- I will assess Documents specially made around the area of this study from different books, Internet journals, proclamations and directives, reports of the branch office made annually, quarterly, etc and sent to main office.

\subsubsection{Sampling Technique}

The researcher had used one Sampling methods (which is Purposive sampling). The reason why he had solely use this method is because of Purposive sampling is best suited to collect data from right person purposely selected, it is useful to reduce time, cost and resource, and it enable to collect valuable data from respondents who have detail information on the issue of this investigation.

\subsubsection{Sampling Unit}

Unite of analysis or sapling unite of this essay were workers from the EHRC Hawassa Branch.

\subsubsection{Sample Size [determination]}

According to Kothari (2004) to select the sample size it should be optimum size, and it could be neither large nor too small. The study population target is, therefore, out of the total population of the target organization (EHRC Hawassa branch $100 \%$ of the workers will take.

\subsubsection{Sources of Data}

\subsubsection{Primary Data Sources}

Primary data is obtained from primary sources by administering survey methods like interviews, questionnaires and observation from the study area as well as the samples used to gather data and lastly from the EHRC Hawassa Branch office.

\subsubsection{Secondary Data Sources}

Secondary data is collected from different books related to training practice and development concept or literature, international journals, different related proclamations and directives, reports and study results of other researchers studied on this topic, etc. 


\subsection{Conceptual Definition of Terms}

This section is devoted to provide basic definition of concepts of words, phrases and statement which will apply on the essay.

Training: is the program made to cope up the workers mind set up and in turn help them aware about the work they do. As a result they will best contribute to better achievements of the works of one organization.

Practice: refers to the implementation process of training and development activities.

Development: is refers to the growth and schedule of training programs and practices in the way it brings the transformation or growth of the organization which would prepare for it.

Change management: refers to a structured approach to transitioning individuals, teams, and organizations from a current state to a desired future state, to fulfill or implement a vision and strategy. It is an organizational process aimed at empowering employees to accept and embrace changes in their current environment.

\subsection{Organization of the Essay Study}

The research report will be organized in to four chapters. Chapter One consists of introduction up to description of the study. Chapter Two presents literature review. Chapter Three contains data presentation and data analysis. Chapter Four describe the Summary, Conclusion and recommendations.

\section{Literature Review}

\subsection{Introduction}

This chapter contains the discussion of theoretical and conceptual issues used to frame the investigation.

\subsection{Training and Development Theoretical Framework}

Thought Training and Development are use synonymously, they, however, are having different meaning "Training prescribes teaching, operational or technical employees for how to do the job for which they were hired. Whereas "Development" is the schedule, program, and process of its implementation that teaching managers and professionals used the skill needed for both present and future jobs (Griffin, 2000).

Training and Development must contain inputs which enable the participants to gain skills, learn theoretical concepts and help acquire vision to look into the distant future. In addition to these there is a need to impart ethical orientation, emphasize on attitudinal changes and stress upon decision making and problem solving abilities.

Nowadays in the world, organization providing and updating knowledge, skill and attitude of the employee is important to five quick responses for competitors in the market, it is common function of human resource management. Because recreating, selecting, orienting and then planning employees to the institution and their job do not ensure success. In most cases, there may be a gap b/n employee knowledge and skills and what the job demands.

Training and development are processes that attempt to provide an employee with information, skills and understanding of the organization and its goals. In addition, training and development are designed to help a person continue to make positive contributions in the form of good performance. Orientation is designed to start the employee in a direction that is compatible with the firm's mission, goals, and culture.

Walking into a new job is often a lonely and confusing event unless Orientation introduces new employees to the organization and to the employee's new tasks, managers, and work groups. The newcomer doesn't usually know what to say or whom to say to it, or even where he or she is supposed to be and conduct the work he employed. Unless something s/he do up on it, getting started is difficult for any new employee simply because being new means not knowing what to expect, having to cope with a major life change (the job), and feeling unsure about the future. These ingredients suggest that "newness anxiety" will naturally be significant.

Though exercising training on new comers and the on job employers made, it is not all training would have the same degree. This means training practices which will made, we talk, up on employees should have different degrees of orientation are needed, depending on the experience, career path, and age of the new employee. For instance: a long year experienced manager who is transferring to another department in the same company at the same job level may need only minimal orientation. However, a first year starter manager who is starting her first full time job after attending management from a commerce school rather needs a fullbrain blown brainstorming orientation. Nevertheless of the trainers, however, any orientation is designed to make the person more comfortable, knowledgeable, and ready to work within the firm's culture, structures, and employee mix. Thus, examining the background of the employee is important in designing the proper type of orientation program.

As Aswathappa (1998) address, job analysis or studying ones employee's background is useful for an HRD manager or other concerned body as much as enough it can helps him/her known what a given job demands from the incumbent terms of knowledge and skills. Training and Development programs can be designed depending on the job requirements. 
Training and development programs as was pointed out earlier help remove performance deficiencies in employees. This is particular true when:- i) the deficiency is caused by lack of ability rather than a lack of motivation to perform, ii) the individual(s) involved have the aptitude and motivation need to learn to do the job better, and (iii) supervisors and peers are supportive of the desired behaviours.

Conducting training practices and development have different contributions to employee's stability at least two ways. Employees become efficient after understanding training. Efficient employees contribute to the growth of the organization. Growth renders stability to the workforce; further, trained employees tend to stay with the organization. They seldom leave the company training makes the employees versatile in operations. Beyond this as Aswathappa (1998) addresses it can help to avoid accidents, scrap and damage to machinery and equipment can be avoided or minimized through training. Even further more it can diminishes job dissatisfaction, complaints, absenteeism, and turnover of employees very well.

\subsubsection{Concepts of Training Practice and Development}

Training:-any attempt to improve employee performance on a current held job or one related to it. This usually means changes in specific knowledge, skills, attitudes or behaviors. To be effective training should involve a learning experience, be a planned organization activity. And be designed in response to identified need. Ideally, training also should be designed to meet the goals of the organization while simultaneously meeting the goal of individual's employees. The term training is often confused with the term development.

Development:-Is learning opportunities do not have to be limited to improving employee's performance on their current jobs. At Ford, for example, a new systems analyst is required to take a course on Ford standards for user's manuals. The content of this training is needed to perform the system analyst job at Ford. The systems analyst however, also may enroll in a course entitled "self-awareness," the content which is not required on the current job. This situation illustrated the different b/n "training" and "development" the focus of "development" the focus of "development" is on the long term to help employees prepare for future work demands, while "training" often focuses on the immediate period to help fix any current deficits in employee's skills. The most effective companies look at training and career development as an integral part of a "human resource development (HRD) program carefully aligned with corporate business strategy (John, 2004).

\subsubsection{Purpose of Training}

The main aim of training is to shorten learning time so that new recruits reach their peak of efficiency as quickly and economically as possible in the way it reduces cost for the organization. Training also aims at improving the performance of existing employees. It also helps people to develop their capacities so that the company can meet most, if not all, its future requirements for manager's supervisors and higher grade professional, technical, sales and productions staff from within the enterprise. In nutshell, the purposes of training include:-

- Improving the quantity of out put

- Improving the quality of output

- Lowering the costs of waste and equipment maintenance

- Lowering the number and costs of accidents

- Lowering the turnovers and absenteeism and

However, increasing on job satisfaction might bring if and only if training can improve the employee's selfesteem (Narayaba, 2000).

\subsubsection{Theories and Trends on Training Practices and Development}

\section{A. Goals of Training}

Training validity:-is the trainees learn skills or acquire knowledge or abilities during the training?

Transfer validity:-Did the knowledge, skills, or abilities learned in training lead to improved performance on the job?

Intra organizational validity:-Is the job performance of a new group of trainees in the same organization that developed the program comparable to the job performance of the original training groups(s)

Inter organizational validity:-Can a training program that has been validated in one organization be used successfully in another firm? These questions (goals) result in different evaluation procedures to examine what, if anything, training and development have accomplished (Ivanccrich, 2003).

\section{B. Choose Trainers and Trainees}

The success of the training program depends on proper selection of the person who performs the training task. Personal characteristics (such as the ability to speak well, to write convincingly, to organize the work of others, to be inventive, and to inspire others to greater achievements) are important factors in the selection of trainers. The process of analyzing needs and developing a training program can be accomplished by company trainers. HR specialists or hired outside consultants who report to the HR manager or other top managers are also used to perform a needs analysis and to conduct the training. 
Although much formal training is performed by professional trainers, often operating supervisors may be the best trainers technically, especially if the training manager helps them prepare the material. Using operating managers as trainers overcomes the frequent criticism that "training is OK in the classroom. But is won't work on the shop floor or back on the job.” The presence of trained trainers is a major factor in whether the training program is successful (Ivanccrich, 2003).

\title{
C. Training and Development Methods
}

Training methods are categorized in to two groups:-

On the job

Off the job methods

On the Job methods: that are applied in the workplace, while the employee is actually working.

Probably the most widely used method of training (formal and informal) is on the job training. It is estimated that more than 60 percent of training occurs on the job. The employee is placed into the real work situation and shown the job and the tricks of the trade by an experienced employee or the supervisor.

Although this program is apparently simple and relatively less costly, if it is not handled properly the costs can be high -damaged machinery, unsatisfied customers, misfiled forms, and poorly taught workers. To prevent these problems, trainers must be carefully selected and trained. The trainee should be placed with a trainer who is similar in background and personality. The trainer should be motivated for training and rewarded for doing it well. The trainer should use effective techniques in instructing the trainee (Ivanccrich, 2003).

\section{Advantage of on the Job Training}

It is the most effective method as trainee learns by experience, making him or her highly competent. Further, the method is least expensive since no formal training is organized. The trainee is highly motivated to lean since he or she is aware of the fact that his or her success on the job depends on the training received.

Finally, the training is free from an artificial situation of a class room. This contributes to the effectives of the program.

Off the job Methods: - away from work place

Organization with the biggest training programs often use off-the job training. A survey of training directors in fortune 500 companies examined their views of which off-the job training techniques were the most effective for specific objectives. The training directors indicated that if knowledge was the objective, it would be best to use programmed instruction. On the other hand, if the training was intended to improve problem-solving skills, then it would be better to use the case method of training (for example, having participant's analyze job -related cases). Research suggests that the most popular methods of instruction for off the job training are lecture-discussion, programmed instruction, and computer-assisted instruction (Ivanccrich, 2003).

\section{Training and Development Process}

According to Gary there are five steps to process training:-

- Need analysis

- Identifies the specific job performance skill

- Analyses the skill and need of the prospective trainee

- Development specific measureable knowledge and performance objectives

The first step is a systematic, objective determination of training need that involves conducting three primary types of analyses. These analyses are used to derive objectives for the training program the three analyses, consist of an organizational analysis a job analysis and person analysis. After compiling the results objective for the training program can be derived. In the second step, instructional design, and produce the training program content, including work books, exercises and activities, here you will probably use techniques. Such as on the job training and computer assisted learning there may be third validation step, in which the buss are worked out of the training program by presenting it to a small representative audience. The fourth steps to implement the program by actually raining the targeted employee group fifth is an evaluation and follow up step, in which management assesses the program's success or failures (Dessler, 2004).

\author{
2.3. Implications and/ Or Benefits of Training Practice and Development \\ 2.3.1. Benefits to the Organization \\ - Leads to improved profitability and/or more positive attitudes towards profit orientation, \\ - Improves the job knowledge and skills at all levels of the organization, \\ - Helps people identify with organizational goals, \\ - Helps employees adjust to change, \\ - Creates an appropriate climate for growth.
}




\subsubsection{Benefits of Individual}

Benefits of individual and in turn ultimately should benefit the organization.

- Helps the individuals in making better decisions and effective problem solving,

- Aids in encouraging and achieving self-development and self-confidence,

- Increases job satisfaction and recognition,

- Provides information for improving leadership, knowledge, communication skill and attitudes. (Aswathappa, 1998).

\subsubsection{The Major Decisions in Planning Training Activities}

- Determine the training need and objectives

- Translate them into programs that meet the need of the selected trainees

- Evaluate the results

\subsubsection{Deterring Training Need and Objectives}

The first issue is to identity training need relevant to the organization objectives. Assessing needs is important because other decisions hinge on it. The content of programs the techniques used and even the trainees chosen depend on the objectives of the training program. Is the training for manager or work processing? Are the trainees experienced? How important is this training to the organization? How much time and money are we willing to invest in it? Which payoff can we anticipate from the training? The importance and relationship of these objectives to organized strategies determine the level of resources committed to training efforts. One ways to identify training needs is within a frame work of three sets of analysis. These are:

-Organizational;

-Job and

-Individual

Organizational Analysis:-Is the process of determining where training is needed? This is a broad look at companywide needs. A thorough analysis might look at organization maintenance, efficiency\& culture. Organization maintenance aims at ensuring a steady supply of critical skills.

Organizational efficiency:- a major objective in the diagnostic model might include checking on productivity, labour costs, output quality or various other measures.

Organizational culture:-The value system or philosophy of the organization. Training can be designed to impart the organization philosophy or values to employees.

Job Analysis:-The job requirements are a valuable source of data to establish training needs. Several approaches to analyzing job identify training needs. Tasks analysts, work sampling, critical incident analysis, and task inventories in which employees indicate how frequently they carry out a particular activity and importance of each activity to the job are all ways to analyze the training needs for a particular job (Milkovich \& Others, 2006).

\subsubsection{To be Effective Training Programs Should Accomplish A Number of Objectives:-}

a) Training must be based on organization and individual needs.

b) Training should address problems that need to be solved. Company reports and records provide clues to the trouble spurts within an enterprise. Records on tardiness, absenteeism, turnover \& accident rates provide objective evidence of the problem.

c) Training program should base on sound theories of learning.

d) Training must be evaluated and modifications in training programs must be made whenever necessary. It is quite unlikely that the task demands are stable, more frequently, because of volatile technology and market condition, the jobs are changing and this requires change in training so that employees meet the current effectiveness standards (Narayaba, 2000).

\subsubsection{Conclusion}

Different scholars address that training (on job) is the main solution to transform the organization from it's now state to the desired future state. Training practices and development is the main issue of change management in human resource development and management.

\section{3. [Methods of] Data Presentation and Analysis \\ 3.1. Data Presentation:}

After that I will use different graphs, tables and percentage analysis in appropriate the data I will collect so as to present it. Then I will use triangulation methods so as to assess or analyze whether or not the data is valid, accurate, and/ or valuable.

At the end I will prepare reports and summit to the concerned body (The academic research committee of ICDE) and by preparing a slide with different presentation tools such as for the quantitative sections of the 
data frequency tables, graphs, charts and for the qualitative section of the data Thematic mapping, Diagrams having the whole concept of the data and preset using overhead projector to the academic staff and/ or examining committee.

\subsection{Methods Data Analysis}

After the data have been collected, the researcher will turn to the task of analyzing them. The analysis of data requires a number of closely related operations such as establishment of categories to raw data through coding, tabulation and drawing statistical inferences. The unwieldy data should necessarily be condensed in to a few manageable groups and tables for further analysis (Kotharii, 1985). Hence, first, I will pass through editing, coding, and entry processes using SPSS to the raw data before I start analysis.

\subsection{Conclusion}

This essay will fulfil its investigation progress by coinciding with the rules and regulations of research outline given by the university. It is so designed now as it is need. However, because of the investigation required at ground in collecting data, gathering data, organizing and presenting data which are investigated, and at final because of the analysis made on the data the structure of this proposal might will change.

\section{Summary}

Training practice and development are very important enough for one organization as crucial as to the field of Human Resources Development Management. This means Training and Development is the field concern with organizational activities which are aimed to bettering individual and group performances in organizational settings and in turn needs to be analyzed as it filled in the gap between what is happening and what should happen.

As different scholars addressed, Integrating cutting-edge research and innovative management practice, this library of titles will serve as an essential resource for human resource professionals, educators, students, and managers in all types of organizations. Among these scholars, Sharon and Elwood (2015) addresses that Organizations are living systems, in a constant state of dynamic evolution so that new Perspectives in Organizational Learning, Performance, and Change is designed to showcase the most current theory and practice in human resource and organizational development, exploring all aspects of the field-from performance management to adult learning to corporate culture.

However in case of the EHRC Hawassa Branch this is not hold true in programming, perhaps especially in implementing well the practices and in turn filling the professional skill, knowledge, and attitude gaps happen in during performing their works. That is why the researcher designed this proposal and scheduled to show how this could be eliminated.

This proposal is as it is tried to shown up at the introduction part, therefore, is the constituents of four parts that are holding four chapters. Each chapter contains very important and very critical elements which are hold as main topics and sub topics to make the investigation ahead very well.

\section{References}

Armstrong, M. (2003). Handbook of employee training and development (5th ed.).

Armstrongs, M. (2006). Handbook of employee training and development (5th ed.).

Aswathappa, K. (1998). Human resource management (3rd ed.). New Delhi: Tata McGraw Hill.

Dessler, G. (2004). Human resource management (3rd ed.). New Delhi: Prentic-Hill of India.

Griffin, W. (2000). Principles and practices of management (9th ed.). India: McGrrew Hill.

Ivanccrich, M. (2003). Human resourc management (9th ed.). Macgrew-Hill.

John, B. (2004). Human resource management (9th ed.). New Delhi: Tata MCfrew-Hill.

Kothari, C. (2004). Research methodology: Methods and techniques. India: New Delhi New Age International.

Kotharii, C. (1985). Research methodology: Chapter two; methods \& techniques. Retrieved from http://shodhganga.inflibnet.ac.in/bitstream/10603/3727/12/12_chapter\%202.pdf.

Milkovich, T., \& Others. (2006). Personal human resource management. Nusiness Publication.

Narayaba, P. (2000). Principles \& practices of management (1st ed.): Konark Publishers University.

Sharon, S. N., \& Elwood, F. H. I. (2015). Approaches to training and development: New perspectives in organizational learning, performance, and change. Third Edition Library of Congress Control Number: 2003103395 ISBN 07382-0698-9. Retrieved from http://www.basicbooks.com. [Accessed 10 January, 2015]. 
5. Proposal Appendices (English Version)

Appendix-A:

Structured Questions prepared to the workers for questioning

2. General Information:

Don't write your name. Boundary demarcation includes the specifying of the administrative area of the town and this helps to contribute for the public peace and security or it helps your town administration area to be peace with the neighbouring rural administration, Please give your answer by putting the sign of ' $x$ ' to the box provided in front of the choices and write your opinions on the space provided.
1. Sex
Male
Female
2. Ages: $15-29$ years
$\square$ 30- 40years
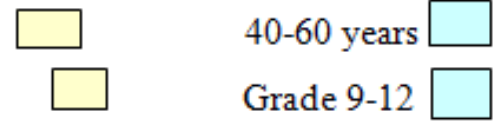
above 60 years.
Diplomas
3. Educational level: Below 9 grade
$\mathrm{MA} / \mathrm{MSC}$ Degree and above
BA/BSC Degree Married
not married
Divorced
Death
4. Marital status:
Less than $500 \operatorname{Birr}$
500-1500Birr
5. Monthly Income:
Greater than 3000 Birr
1500-3000 Birr
Less than 5 years
5-10 years
11-15
6. Years worked in this organization:
years
$16-20$ years
Greater than 20 years

\section{Questions Related to the Research or Investigation Topic of TD\&P:}

Letters of instruction: The objective of the questionnaire is to collect relevant data for academic research essay made on training practices and development: the case of Ethiopian Human Rights Commission Hawassa Branch. The research is conducted mainly in order to develop scholarly knowledge of the researcher and in turn, wining scholarship competitions. Moreover its findings are significant in solving the identified challenges. Hence, genuine cooperation and commitment of respondents in properly filling this questionnaire is vital. I want to mind you also, the data is used only for academic purposes, not for otherwise else. And it will treat with greater confidentiality. Thus you are humbly required to give your genuine answer to the following questions.

\section{Thank you for your Cooperation!}

1. Is the training practice conducted in the commission or organization you are working on now is need based?
A. strongly agree
B. Agree
C. Neutral partially agree arely

2. If need assessment have been conducted state briefly when and how the assessment conducted on the space below in the blank space?

3. If need assessment is conducted, to what extent that the assessment is appropriate to identify the gap in skill, knowledge, and competence between the desired and the actual performance levels?
A. Very high
B. High
C. Medium
D. low
E. very low

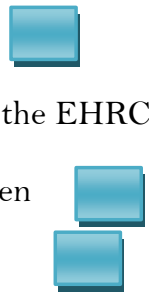

4. How often the EHRC Hawassa branch conducts need assessment of its training development and practice program?
A. Very often
B. Often
C. Sometimes
D. Rarely
E. Very Rarely

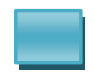

5. EHRC Hawassa branch has the practice of a training program before conducting any training.
A. Strongly agree
C. Neutral
B. Agree
D. Disagree
E. Strongly Disagree 
6. To what extent that the criteria used to select trainees are based on the objectives stated there on the training development and practice program?
A. Very High
C. Medium

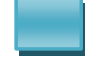
E. Very low
B. High
D. Low

7. If your answer for question ' 6 ' above is 'low' or 'very low' what do you think the reason (s) is/ are? Please describe on the blank space below?

8. If you took any training with ion the past few years, how do you see its impact towards improvement of your performance on jobs?
A. Very high
C. Medium

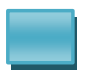
E. Very low
B. High
D. Low

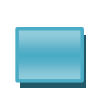

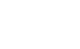

9. If you took any training with ion the past few years, to what extent is it connected to your job?
A. Very high
B. High
C. Medium
D. Low
E. Very low

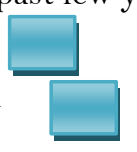

10. Are there any training development and practice evaluation mechanisms or methods in the EHRC Hawassa branch?
A. Yes
B. No

11. If your answer for question number " 9 " above is 'Yes', are you involved in the evaluation of the training development and practice program of your branch office?
A. Strongly Agree
C. Neutral

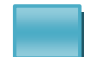
E. Strongly Disagree
B. Agree
D. Disagree

12. If you have been involved in the evaluation of the training development and practice program of the EHRC Hawassa branch how do you rate the objectives of the evaluation?
A. Very high
B. High
C. Medium
D. Low
E. Very low

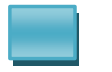

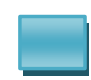

13. How do you overall rating of training development and practice program of EHRC Hawassa Branch?
A. Very poor
C. Excellent
E. Very good
B. Poor
D. Good

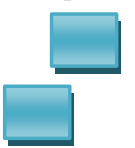

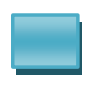

14. How far the EHRC Hawassa branch link the difference training offered to employee's future development?
A. Very high
C. Good

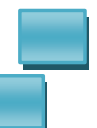
E. Very poor
B. High
D. Poor

15. What is the overall assessment on the training that conducted contribute for the achievement of the EHRC Hawassa branch goal at particular and the HER Commission I general?
A. Very high
C. Medium
E. Very low
B. High
D. Low

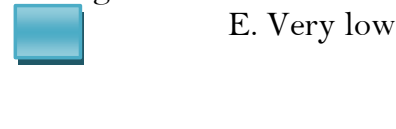

16. What is your overall rating for EHRC Hawassa branch training development and practice facilities?
A. Excellent

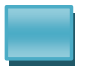
C. Good
E. Very Poor
B. Very Good
D. Poor

17. How much the tmanng development and practi_ nat are conducted on EHRC Hawassa branch contribute for the achievement of its objectives and the Commission's objective in general?
A. Very high
C. Medium

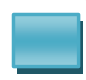
E. Very Low

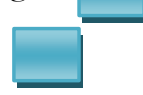



B. High
D. Low

18. What is your opinion about the appropriateness of the training development and practice environment of EHRC Hawassa branch?
A. Excellent
C. Good

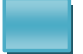
E. Very Poor
B. Very Good
D. Poor

19. Write down any additional Comments you want to rise on the training development and practice programs of EHRC Hawassa branch.

\section{Thank you a lot for your Cooperation!!!}

\section{Appendix-B}

Questions provided for conducting interview with the commissions managers or upper leaders:

\section{General information}

Don't write your name. Boundary demarcation includes the specifying of the administrative area of the town and this helps to contribute for the public peace and security or it helps your town administration area to be peace with the neighbouring rural administration, Please give your answer by putting the sign of ' $x$ ' to the box provided in front of the choices and write your opinions on the space provided.
1. Sex
Male
Female

2. Ages: 15-29 years 30- 40years
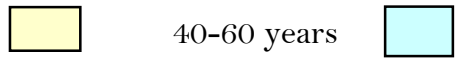
above 60 years.

3. Educational level: Below 9 grade

Grade 9-12

Diplomas

\section{BA/BSC Degree \\ MA/MSC Degree and above}

4. Marital status:

Married not married

Divorced

5. Monthly Income:

Less than 500 Birr

1500-3000 Birr

Greater than 3000 Birr

6. Years worked in this organization:

Less than 5 years
500-1500Birr
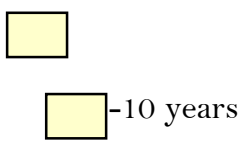

Death

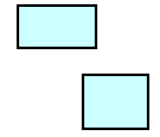

Greater than 20 years

\section{Questions related to the Research or Investigation Topic of TD\&P:}

Letters of instruction: The objective of the questionnaire is to collect relevant data for academic research essay made on training practices and development: the case of Ethiopian Human Rights Commission Hawassa Branch. The research is conducted mainly in order to develop scholarly knowledge of the researcher and in turn, wining scholarship competitions. Moreover its findings are significant in solving the identified challenges. Hence, genuine cooperation and commitment of respondents in properly filling this questionnaire is vital. I want to mind you also, the data is used only for academic purposes, not for otherwise else. And it will treat with greater confidentiality. Thus you are humbly required to give your genuine answer to the following questions.

\section{Thank you for your Cooperation!}

2. Do you have a training development and pratcice Policy?

3. What types of training development and practice program or policy that the EHRC Hawassa branch use?

4. How the your organization conduct need assessment before conducting training?

5. How do you Evaluate the Impact of training development and practice program of the EHRC Hawassa branch?

6. What are the focus areas of training development and practice program on which your organization use? 


\section{Field Research Plan}

To conduct this research study, every activity needs a scheduled duration .For this reason, the work plan has prepared properly in the following table: Based on this idea, the following table shows the series of activities and time frame of the study.

\begin{tabular}{|c|c|c|c|c|c|c|c|}
\hline \multirow[t]{2}{*}{ No. } & \multirow[t]{2}{*}{ Activities } & \multicolumn{6}{|c|}{ The time or months in which activities will performed } \\
\hline & & January & February & March & April & May & June \\
\hline \multirow[t]{4}{*}{1} & Thesis Preparation \& approval & Xxxxxxxx & & & & & \\
\hline & Planning of research activity & $\operatorname{xxxxxxxxx}$ & & & & & \\
\hline & Literature review & $\mathrm{Xxxxxxxxx}$ & & & & & \\
\hline & Sample size determination & $\operatorname{xxxxxxxxx}$ & & & & & \\
\hline \multirow[t]{5}{*}{2} & Data collection \& tabulation & & $\mathrm{xxxxxxx \textrm {x }}$ & & & & \\
\hline & Data collection & & $\mathrm{xxxxxx \times x}$ & & & & \\
\hline & Data entry & & & & & & \\
\hline & Data cleaning & & & & $\operatorname{xxxxx}$ & & \\
\hline & Tabulation & & & & $\operatorname{xxxxx}$ & & \\
\hline 3 & Submission of Chapter One & & & & $\operatorname{xxxxx}$ & & \\
\hline 4 & Chapter two & & & & $\operatorname{xxxxx}$ & & \\
\hline 5 & Chapter three & & & & $\operatorname{xxxxx}$ & & \\
\hline 6 & $\begin{array}{l}\text { Initial data analysis submission of } \\
\text { preliminary finding }\end{array}$ & & & & $\begin{array}{l}\operatorname{xxxxxx} \\
\operatorname{xxxx}\end{array}$ & & \\
\hline \multirow[t]{4}{*}{7} & Submission of Chapter Four & & & & $\operatorname{xxxxx}$ & & \\
\hline & Revised Data analysis & & & & $\mathrm{xxxxx}$ & & \\
\hline & Report writing & & & & $\mathrm{Xxxxx}$ & & \\
\hline & Incorporate final comments & & & & $\operatorname{xxxxx}$ & & \\
\hline 8 & Submission of final copy & & & & $\mathrm{Xxxx}$ & & \\
\hline 9 & Final Presentation & & & & $\mathrm{Xxxx}$ & & \\
\hline
\end{tabular}

